\title{
EFFECT OF TRAINING AND WHEAT GERM OIL ON THE PRECORDIAL T WAVE OF MIDDLE-AGED MEN
}

\author{
J. L. MAYHEW, M.Sc., B.Sc. \\ Dept. of Health, P.E. and Recreation, Appalachian State University, North Carolina,
}

\section{Introduction}

Substantial evidence has been amassed to indicate that progressive endurance exercise improves the cardiovascular function of sedentary men (Cureton, 1966; Hanson, et al., 1968; Saltin, 1969). Primary evidence has been the positive alterations in the electrocardiogram (Tuttle and Korns, 1941; Wolf, 1953; Lloyd-Thomas, 1961). The most noticeable change in the ECG has been in the $T$ wave, which has been used to designate ventricular repolarization (Guyton, 1966). Increases in the amplitude of the $T$ wave with training are well documented (Tuttle and Korns, 1941; Wolf, 1953; Beckner and Winsor, 1954; Cureton, 1958; Rose and Dunn, 1964) in both athletes (Beckner and Winsor, 1954; Rose and Dunn, 1964) and middle-aged subjects (Cureton, 1958). However, it has been indicated (Cureton, 1958) that if training is too strenuous and/or prolonged the $T$ wave amplitude may decrease.

The addition of a wheat germ oil dietary supplement to programmes of hard physical training has produced favourable though inclusive effects on the neurological function of the heart (Cureton, 1955, 1959, 1963). Cureton and Pohndorf (1955) indicated significant improvement in the $T$ wave amplitude of middle-aged men who supplemented their training with wheat germ oil; a training group taking placebos also made significant improvements and was insignificantly different from the WGO group. However, a trend in favour of WGO was established by the authors. Using U.S. Navy underwater swimmers, Cureton (1963) again showed significant improvements in both the supplemented and unsupplemented groups but insignificant differences between the two groups. Poiletman and Miller (1968) found statistically insignificant relationships between training and $T$ wave amplifications and between WGO and T wave amplification in cross-country runners. A trend in favour of improved $T$ wave amplitude in the WGO group was noted by the authors.

Conclusive evidence supporting the benefits of supplementing hard physical training with a wheat germ oil was lacking. The changes made by training dominate the results of most studies, with the influences of WGO relegated to a secondary position.
Therefore, the purpose of this study was to determine the effect of endurance training with and without wheat germ oil supplementation on the amplitude of the $T$ wave of the ECG of middle-aged men.

\section{Experimental Design}

The subjects used for this study were 25 sedentary male volunteers. Age and anthropometric data of the subjects at the beginning of the study is presented in Table 1. Nineteen of the subjects participated in a 20-week endurance training programme; six subjects served as controls. No attempt was made to regulate the diet of the subjects, although they were encouraged not to change their dietary habits during the study.

TABLE 1. Age and Anthropometric Data of Subjects

\begin{tabular}{lrr} 
Variable & Mean & \multicolumn{1}{c}{ S.D. } \\
Age, yrs. & 38.61 & 10.96 \\
Height, ins & 69.75 & 2.71 \\
Weight, lbs. & 178.61 & 19.15
\end{tabular}

Range

24.7. 62.0

65.8- 75.5

$142.2-219.2$

The subjects were tested prior to training (T-1), following ten weeks of training (T-2), and following 20 weeks of training (T-3).

The test consisted of a precordial electrocardiogram (lead $\mathrm{V}_{4}$ ) recorded during the last ten seconds of each minute of (1) sitting position, (2) a two-minute bicycle ergometer ride $(25 \mathrm{Kg}-\mathrm{m} / \mathrm{sec}$. at $60 \mathrm{rpm})$, and (3) a tenminute recovery in the sitting postition. The voltage scale for the ECG was the universally accepted ten millimeters of pen deflection per one millivolt. All recordings were made on a physiograph (response frequency $=0.06$ $-250 \mathrm{cps}$ ).

No food was ingested for at least three hours prior to the test and no beverage was consumed for at least one hour preceding the test. Upon arriving at the laboratory each subject reclined for 15 minutes prior to testing.

The training programme consisted of walking, jogging, and rhythmic exercises as prescribed by Cureton (1965). The subjects attended training sessions three 
times per week. Each training session was led by the primary researcher who encouraged each subject to maintain a vigorous pace. Training sessions lasted an average of 45 minutes each, with the programme made more strenuous by increasing the intensity of the work over the 20 week period.

At the conclusion of ten weeks of training the subjects were divided into three matched groups based on their mile-run time. Group $A(N=6)$ received a wheat germ oil supplement, ten capsules daily, six minims (1 millilitre) each. Group B $(\mathrm{N}=6)$ received non-nutritive placebos (ten capsules daily). Group C (N $=7$ ) received no supplementation. The subjects were instructed to take the supplements as far from meals as possible on nontraining days and immediately after the exercise session on training days (Cureton, 1956). All supplements were taken with water and administered on a double blind basis.
Statistical Procedure

After ten weeks of endurance exercise, the training subjects $(N=19)$ had made significant increases $(0.05$ level) over the controls $(N=6)$ in $T$ wave amplitude in (1) sitting rest, (2) second minute of a bicycle ergometer ride $(25 \mathrm{Kg}-\mathrm{m} / \mathrm{sec}$. at $60 \mathrm{rpm})$, (3) first minute of recovery, and (4) third minute of recovery. An insignificant trend in favour of the training subjects was shown in the second, seventh, eighth, and tenth minutes of recovery (Table 2).

\section{Results and Discussion}

The analysis of covariance (ANCOVA) was used to determine if significant differences existed at T-2. The ANCOVA was also used to determine if significant differences existed among the three groups at T-3. If a significant $F$ ratio was found at T-3 Duncan's Multiple Range was used to determine which group was significantly different from the other groups.

TABLE 2. Effects of Ten Weeks of Training on the T Wave

\begin{tabular}{|c|c|c|c|c|c|c|c|}
\hline \multirow[t]{2}{*}{ GROUP } & \multirow[t]{2}{*}{ T WAVE } & \multirow[t]{2}{*}{ UNITS } & \multicolumn{2}{|c|}{ T-1 } & \multicolumn{2}{|c|}{$\mathrm{T}-2$} & \multirow{2}{*}{$\begin{array}{r}\text { Mean Chan } \\
T-1 \text { to } T\end{array}$} \\
\hline & & & Mean & S.D. & Mean & S.D. & \\
\hline Tr. & Sitting & MM & 4.05 & 2.93 & 6.00 & 2.38 & $1.95 *$ \\
\hline Con. & rest & & 3.83 & 1.83 & 3.83 & 1.16 & 0.00 \\
\hline Tr. & $1 \mathrm{~min}$. & $\mathbf{M M}$ & 4.73 & 2.83 & 4.73 & 2.74 & 0.00 \\
\hline Con. & ex. & & 4.66 & 2.50 & 4.16 & 2.63 & -0.50 \\
\hline Tr. & 2 mins. & MM & 3.10 & 1.90 & 4.70 & 1.77 & $1.60^{*}$ \\
\hline Con. & ex. & & 2.86 & 1.02 & 2.50 & 0.48 & -0.36 \\
\hline Tr. & $1 \mathrm{~min}$. & $\mathbf{M M}$ & 4.27 & 2.87 & 5.41 & 2.18 & $1.14^{*}$ \\
\hline Con. & rec. & & 3.70 & 1.46 & 3.30 & 1.32 & -0.40 \\
\hline Tr. & 2 mins. & MM & 5.31 & 3.85 & 7.73 & 2.46 & 2.42 \\
\hline Con. & rec. & & 4.66 & 1.21 & 5.83 & 0.98 & 1.17 \\
\hline Tr. & 3 mins. & MM & 4.47 & 2.72 & 6.54 & 2.72 & $2.07^{*}$ \\
\hline Con. & rec. & & 3.33 & 1.37 & 2.00 & 0.30 & -1.33 \\
\hline Tr. & 4 mins. & MM & 5.43 & 2.51 & 6.21 & 2.69 & 0.78 \\
\hline Con. & rec. & & 5.36 & 1.45 & 6.13 & 0.69 & 0.77 \\
\hline Tr. & 5 mins. & MM & 6.35 & 2.35 & 7.03 & 1.97 & 0.68 \\
\hline Con. & rec. & & 4.28 & 0.98 & 5.28 & 0.96 & 1.00 \\
\hline Tr. & 6 mins. & $\mathbf{M M}$ & 4.21 & 2.72 & 5.89 & 1.69 & 0.68 \\
\hline Con. & rec. & & 3.50 & 1.04 & 4.66 & 0.81 & 1.16 \\
\hline Tr. & 7 mins. & $\mathbf{M M}$ & 3.01 & 2.63 & 4.21 & 2.91 & 1.20 \\
\hline Con. & rec. & & 5.00 & 2.09 & 2.50 & 0.37 & -2.50 \\
\hline Tr. & 8 mins. & $\mathbf{M M}$ & 4.96 & 2.13 & 5.72 & 1.71 & 0.76 \\
\hline Con. & rec. & & 3.56 & 0.65 & 4.01 & 0.82 & 0.45 \\
\hline Tr. & 9 mins. & MM & 5.02 & 2.21 & 5.65 & 1.68 & 0.63 \\
\hline Con. & rec. & & 3.40 & 1.05 & 4.31 & 1.48 & 0.91 \\
\hline Tr. & 10 mins. & MM & 3.52 & 0.36 & 5.15 & 1.89 & 1.63 \\
\hline Con. & rec. & & 3.16 & 1.16 & 4.00 & 0.89 & 0.84 \\
\hline
\end{tabular}

*Significant at the 0.05 level. 
The increases in $T$ wave amplitude agreed with the findings of Wolf (1953), Beckner and Winsor (1954), and Cureton (1958). The tendency for the $T$ wave amplitude to become elevated in excess of the resting recording in the minutes immediately following exercise (first through fifth) and to return to or below the resting level in the later stages of recovery coincided with the observations of Lloyd-Thomas (1961), Kiessling, et. al. (1964), Rose, et. al. (1966), and Joseph (1970).

At T-2 there were no significant differences among
Groups $A, B$, and $C$ in $T$ wave amplitude in any of the 13 conditions. At T-3 Group A (WGO) had made significantly greater changes than Groups B (Placebo) and C (no capsules) in the (1) second minute of recovery, (2) fifth minute of recovery, and (3) sixth minute of recovery. An insignificant trend in favour of the wheat germ oil group was present in the seventh and eighth minutes of recovery. Groups $\mathbf{A}$ and $\mathbf{C}$ were significantly better than Group B in the ninth and tenth minutes of recovery, but were insignificantly different from one another (Table 3).

TABLE 3. Effects of WGO and Training on the T Wave.

\begin{tabular}{|c|c|c|c|c|c|c|c|}
\hline \multirow[t]{2}{*}{ GROUP } & \multirow[t]{2}{*}{ T WAVE } & \multirow[t]{2}{*}{ UNITS } & \multicolumn{2}{|c|}{ T.2 } & \multicolumn{2}{|c|}{ T.3 } & \multirow[b]{2}{*}{$T-1$ to $T-3$} \\
\hline & & & Mean & S.D. & Mean & S.D. & \\
\hline $\begin{array}{l}\text { WGO } \\
\text { Placebo } \\
\text { Tr. } \\
\text { WGO } \\
\text { Placebo } \\
\text { Tr. } \\
\text { WGO } \\
\text { Placebo } \\
\text { Tr. } \\
\text { WGO } \\
\text { Placebo } \\
\text { Tr. } \\
\text { WGO } \\
\text { Placebo } \\
\text { Tr. } \\
\text { WGO } \\
\text { Placebo } \\
\text { Tr. } \\
\text { WGO } \\
\text { Placebo } \\
\text { Tr. } \\
\text { WGO } \\
\text { Placebo } \\
\text { Tr. } \\
\text { WGO } \\
\text { Placebo } \\
\text { Tr. } \\
\text { WGO } \\
\text { Placebo } \\
\text { Tr. } \\
\text { WGO } \\
\text { Placebo } \\
\text { Tr. } \\
\text { WGO } \\
\text { Placebo } \\
\text { Tr. } \\
\text { WGO } \\
\text { Placebo } \\
\text { Tr. }\end{array}$ & $\begin{array}{c}\begin{array}{c}\text { Sitting } \\
\text { rest }\end{array} \\
\begin{array}{c}1 \text { min. } \\
\text { ex. }\end{array} \\
2 \text { mins. } \\
\text { rex. } \\
1 \begin{array}{c}\text { min. } \\
\text { rec. }\end{array} \\
2 \text { mins. } \\
\text { rec. } \\
3 \text { mins. } \\
\text { rec. } \\
4 \text { mins. } \\
\text { rec. } \\
5 \text { mins. } \\
\text { rec. } \\
6 \text { mins. } \\
\text { rec. } \\
7 \text { mins. } \\
\text { rec. } \\
8 \text { mins. } \\
\text { rec. } \\
9 \text { mins. } \\
\text { rec. } \\
\text { rec. }\end{array}$ & $\begin{array}{l}\text { MM } \\
\mathbf{M M} \\
\mathbf{M M} \\
\mathbf{M M} \\
\mathbf{M M} \\
\mathbf{M M} \\
\mathbf{M M} \\
\mathbf{M M} \\
\mathbf{M M}\end{array}$ & $\begin{array}{l}6.50 \\
5.16 \\
6.28 \\
4.50 \\
5.66 \\
4.14 \\
4.86 \\
5.00 \\
4.30 \\
5.48 \\
6.03 \\
4.81 \\
7.50 \\
7.83 \\
7.85 \\
6.70 \\
8.01 \\
5.15 \\
5.76 \\
6.03 \\
6.74 \\
7.78 \\
6.50 \\
6.85 \\
6.66 \\
5.33 \\
5.71 \\
5.16 \\
3.33 \\
4.14 \\
6.65 \\
4.50 \\
5.98 \\
6.36 \\
4.53 \\
6.01 \\
5.83 \\
4.33 \\
5.28\end{array}$ & $\begin{array}{l}3.08 \\
2.85 \\
1.11 \\
2.25 \\
3.20 \\
2.91 \\
2.50 \\
1.89 \\
0.93 \\
2.62 \\
2.61 \\
1.42 \\
3.44 \\
2.56 \\
1.67 \\
2.27 \\
1.07 \\
1.54 \\
2.13 \\
3.25 \\
2.95 \\
2.43 \\
1.76 \\
1.81 \\
1.86 \\
2.06 \\
1.11 \\
2.85 \\
3.38 \\
2.73 \\
1.71 \\
1.78 \\
1.13 \\
1.74 \\
1.94 \\
0.93 \\
2.22 \\
2.42 \\
0.75\end{array}$ & $\begin{array}{l}7.16 \\
5.16 \\
6.14 \\
5.50 \\
3.16 \\
5.57 \\
4.95 \\
5.78 \\
4.71 \\
6.58 \\
6.00 \\
5.71 \\
9.16 \\
7.66 \\
7.42 \\
4.38 \\
3.18 \\
5.57 \\
4.46 \\
5.73 \\
7.47 \\
8.21 \\
6.28 \\
6.62 \\
7.50 \\
5.16 \\
5.57 \\
4.66 \\
3.38 \\
4.28 \\
7.40 \\
5.10 \\
5.97 \\
7.25 \\
4.61 \\
6.38 \\
6.66 \\
4.16 \\
6.28\end{array}$ & $\begin{array}{l}2.85 \\
2.04 \\
1.86 \\
3.14 \\
2.22 \\
2.99 \\
1.72 \\
1.41 \\
1.60 \\
1.99 \\
1.26 \\
1.49 \\
2.78 \\
1.75 \\
1.39 \\
3.03 \\
2.94 \\
0.78 \\
3.89 \\
3.24 \\
1.50 \\
1.39 \\
1.56 \\
0.94 \\
1.76 \\
1.94 \\
0.78 \\
3.20 \\
2.92 \\
2.36 \\
1.61 \\
1.97 \\
1.07 \\
1.34 \\
2.03 \\
0.89 \\
0.81 \\
2.48 \\
0.95\end{array}$ & $\begin{array}{c}0.46 \\
0.00 \\
-0.14 \\
1.00 \\
-2.50 \\
1.43 \\
0.09 \\
0.78 \\
0.41 \\
1.10 \\
-0.03 \\
0.90 \\
1.66^{*} \\
0.17 \\
-0.43 \\
-2.32 \\
-4.83 \\
0.42 \\
-1.30 \\
-0.30 \\
0.73 \\
0.43^{*} \\
-0.22 \\
-0.23 \\
0.94^{*} \\
-0.17 \\
-0.14 \\
-0.50 \\
0.05 \\
0.14 \\
0.85 \\
0.60 \\
-0.01 \\
0.89 \\
0.08 \\
0.37 \\
0.83 \\
-0.17 \\
1.00\end{array}$ \\
\hline
\end{tabular}

*Significant at the 0.05 level. 
The addition of wheat germ oil to a strenuous endurance training programme produced significant changes and certain positive trends toward amplification of the $T$ wave of the ECG of middle-aged men in post-exercise recovery. The unsupplemented and placebo groups showed general decreases in $\mathrm{T}$ wave amplitude from the tenth to twentieth week of training, indicating that the training may have been so strenuous as to be fatiguing. Wheat germ oil appeared to counteract such a trend. This agreed with the findings of Cureton and Pohndorf (1955), Cureton (1963), and Poiletman and Miller (1968).
However, the small increases in some of the minutes of recovery did not support the assumption that wheat germ oil offered great benefit to a strenuous programme which is contradictory to other findings (Cureton and Pohndorf, 1955; Cureton, 1959). Perhaps the resistance of the wheat germ oil group to decreases in the $T$ wave amplitude with strenuous training may indicate some minor benefit as far as competitive conditioning is concerned; however, no inference from middle-aged subjects to competitive athletes was warranted or justified.

References

1. BECKNER, G. L. and T. WINSOR. “Cardiovascular Adaptions to Prolonged Effort.” Cir., 9:835-846, 1954.

2. BRAMWELL, C. and R. ELLIS. "Some Observations on the Circulatory Mechanism in Marathon Runners." Quart. J. Med., 24:329-346, 1931.

3. CARLILE, F. and U. CARLILE. "Physiological Studies of Australian Olympic Swimmers in Hard Training." Australian J. Phys. Ed., 23:5-34, 1961.

4. CURETON, T. K. and R. H. POHNDORF. "Influences of Wheat Germ Oil as a Dietary Supplement in a Program of Conditioning Exercises with Middle-Aged Subjects.” Res. Quart., 26:391-407, 1955.

5. CURETON, T. K. "Physical Fitness: How to Earn it and Keep it with Some Relationship to Nutrition." J. Phys. Ed., 54:3-14, 1956.

6. CURETON, T. K. "Effects of Longitudinal Physical Training on the Amplitude of the Highest Precordinal T-Wave of the ECG." Med. Sportiva, 12:259-281, 1958.

7. CURETON, T. K., et al. "Effects of Physical Training and a Wheat Germ Oil Dietary Supplement Upon the T-Wave of the ECG and the Bicycle Ergometer Endurance Test." Med. Sportiva, 10:490-505, 1959.

8. CURETON, T. K. "Improvement in Physical Fitness Associated with a Course of U.S. Navy Underwater Trainees, with and without Dietary Supplements." Res. Quart., 34:440-453, 1963.

9. CURETON, T. K. Physical Fitness and Dynamic Health. New York: Dial Press, 1965. Pp. 102-162.

10. CURETON, T. K. "The Relative Value of Various Exercise Programs to Protect Adult Human Subjects from Degenerative Heart Disease." Cited in W. Rabb (ed.), Prevention of Ischemic Heart Disease. Illinois: C. C. Thomas, 1966. Pp. 321-330.

11. GUYTON, A. C. Textbook of Medical Physiology. Pennsylvania: W. B. Saunders, 1966. P. 197.

12. HANSON, J. H., et al. "Long-Term Physical Training and Cardiovascular Dynamics in Middle-Aged Men," Cir., 38:783-799, 1968.

13. JOSEPH, J. "The Exercise-Influenced T Wave and its Relation to Sustained Treadmill Running." J. Sports Med., 10:91-95, 1970. 
14. KIESSLING, C. E., et al. "A Study of T Wave Changes in the Electrocardiograms of Normal Individuals." Am. J. Card., 13:598-602, 1964.

15. LLOYD-THOMAS, H. G. "The Effect of Exercise on the Electrocardiogram of Healthy Subject." Bri. Heart J., 23:260-270, 1961 .

16. POILETMAN, R. M. and H. A. MILLER. "The Influences of Wheat Germ Oil on the Electrocardiographic T Wave of the Highly Trained Athlete." J. Sports Med., 8:26-33, 1968.

17. ROSE, K. D. and F. L. DUNN, Physiology of Running Studied by Use of Radio Telemetry." J. Sports Med., $14: 3-15,1964$.

18. ROSE, K. D., et al. "Serum Electrolyte Relationship to Electrocardiographic Changes in Exercising Athletes." J. A. M. A., 195:111-114, 1966.

19. SALTIN, B. “Physiological Effects of Physical Conditioning.” Med. Sci. Sports, 1:50-56, 1969.

20. TUTTLE, W. W. and M. KORNS. "Electrocardiographic Observations on Athletes Before and After a Season of Physical Training.” Am. Heart J., $21: 104107,1941$.

21. WOLF, J. G. "Effects of Posture and Muscular Exercise on the Electrocardiogram." Res. Quart., 24:475-490, 1953.

\section{Book Review}

“SCIENCE AND SPORT, THE MEASUREMENT AND IMPROVEMENT OF PERFORMANCE”.

Vaughan Thomas

Faber \& Faber, London. $1970 \quad$ pp213 $\quad £ 2.25$.

This book is a valuable addition to the library dealing with sport in one aspect or another. It takes its place near the left of the shelf as it is relatively elementary - it should be one of the listed texts for GCE Human Biology. A list of further reading is given wisich is selective but the reader would be well advised to read this volume first so that he has some understanding of the merits of the recommended books. The controversial character of the author comes through in many ways and his references to his personal experience would be immodest if they were not factual. He tends to be severe on sports scientists who disagree with his "test to destruction" when his subjects reach states of unconsciousness because he has not perceived any ill-effects. Yet he monitors the electrocardiogram during exercise to detect abnormalities, inter alia, and he is cautious about moving a man with a chest injury in case of a rib fracture. One has the feeling that because abnormalities of brain function or minor personality changes cannot be detected by the current crude techniques, he considers the risk so minor it can be disregarded. It is a fair analogy that the very rare death during exercise often has an abnormality of the heart in these cases; it is asserted that the cerebral circulation has $20 \%$ anomalies. Inevitably, one of these cases of induced coma will eventually show serious after effects. No doctor would like to take the most minimal risk with any subject other than himself. This ethical question apart - and some minor misprints like Fig. 6 instead of Fig. 7 on page 80 - why not suggest this book as a suitable present from an admiring relative?

D. E. MACKAY 